\title{
ANTROPOTÉCNICA Y OCIOSIDAD. EJERCITARSE PARA LLEGAR A SER OCIOSO
}

\author{
ANTHROPOTECHNICS AND IDLENESS. EXERCISE TO BECOME IDLE
}

Andrés Díaz Velasco ${ }^{1}$

\section{Resumen}

El propósito central de este escrito es argumentar en favor de las formas de vivir ociosas basadas en ejercicios prácticos de ociosidad. Para ello, se contempla en primera instancia la antropología filosófica de Peter Sloterdijk, según la cual el hombre se produce a sí mismo viviendo su vida en distintas formas de ejercicio. En seguida, el texto contrasta esta tesis con los planteamientos de Michel Foucault respecto a la vida como obra de arte. Se finaliza estableciendo la tesis de que ser ocioso no significa simplemente no-hacer-nada, en cuanto que se trata de una actitud vital absolutamente virtuosa, generosa y creativa que se adquiere conforme a un cuidadoso ejercicio de la libertad y la espontaneidad.

Palabras claves: ociosidad; antropotécnica; ascesis; ejercicio; pereza

\section{Abstract}

The central purpose of this paper is to argue for idle ways of living, based on practical exercises of idleness. For this, the philosophical anthropology of Peter Sloterdijk is contemplated, according to which man produces himself by living his life in different forms of exercise. Then, the text contrasts this thesis with the approach of Michel Foucault about life as a work of art. It ends by establishing the proposition that to be lazy does not mean just not-doing-nothing, but that it is an absolutely virtuous, generous and creative attitude to life that is acquired under a careful exercise of freedom and spontaneity.

Keywords: idleness; anthropotechnic; asceticism; exercise; laziness

Fecha de recepción: 23 de octubre de 2015

Fecha de aprobación: 4 de marzo de 2016

Para citar este artículo:

Díaz, A. (2016). Antropotécnica y ociosidad. Ejercitarse para llegar a ser ocioso. Lúdica Pedagógica, (23), $109-118$.

1 Magíster en Filosofía por la Universidad del Rosario. Docente investigador de la Universidad Pedagógica Nacional. Correos electrónicos: andresdiazvelasco@gmail.com, adiazv@pedagogica.edu.co 
Somos desiertos, pero desiertos poblados de tribus, de faunas y de floras. Empleamos el tiempo en colocar esas tribus, en disponerlas de otra forma, en eliminar algunas, en hacer prosperar otras. Pero todas esas poblaciones, todas esas muchedumbres, no impiden el desierto, que es nuestra ascesis misma; al contrario, lo habitan, pasan por él, sobre él. [...] El desierto, la experimentación con uno mismo, es nuestra única identidad, la única posibilidad para todas las combinaciones que nos habitan.

Gilles DELEUZE. Diálogos (CON CLAIRE PARNET). 2004

\section{INTRODUCCIÓN}

Antes que disociar el planteamiento según el cual no se habla más que de palabras a las cuales el sentido les puede llegar de diversas fuentes, y no necesariamente de experiencias ininteligibles por sí mismas que las palabras solo pueden recubrir como un ficticio y maleable ropaje histórico, resulta conveniente asumir una suerte de cartografía geológica básica (Deleuze y Guattari, 1997) de la ociosidad. Esta perspectiva permitiría exponer sus rugosidades contraponiendo al simplista productivismo esclavista, el sentido de una edad de ocio (Illich, 2006) en la cual, siguiendo a Sloterdijk (2003), los hombres no son conducidos ni se conducen a sí mismos. Esto es, ir más allá del sentido enclaustrado en la industria del entretenimiento, por un lado, y en las actividades del tiempo libre, por el otro.

Así las cosas, vale la pena empezar por el hecho, bastante conocido, de que la raíz gramatical de "nuestro" ocio es el otium latino, voz culta que según la etimología hacía referencia al "tiempo disponible para hacer algo por gusto [y] no por deber" (Gómez de Silva, 2006, p. 495). De este modo, la expresión implicaba 'reposo', no como pausa de la acción, sino como una acción en sí misma, la cual implica más que el mero no-hacer-nada, porque remite a la contemplación. En este sentido, la expresión negocio - según Pieper (2003), el negativo del ocio o neg-otium en latín一, significaba para los grecorromanos la ocupación en actividades obligatorias - por lo cual este autor traduce $\alpha \sigma \chi 0 \lambda \eta$ ' como 'estar no ocioso' ya que no específicamente como 'trabajo' o 'trabajar'2_.

2 Sin embargo, la traducción más común es efectivamente 'trabajo', aunque también se la puede encontrar como 'ocuparse', o finalmente, según la traducción de Manuel Briceño Jáuregui de La política de Aristóteles (Instituto Caro y Cuervo, 1989), como 'no descanso', la cual se hermana a la expre-

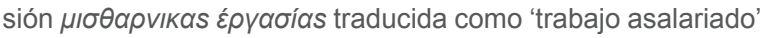
(véase especialmente 1337a y 1337b).
Lo que sobresale de esta significación clásica, expuesta magistralmente por Séneca (2010), es el hecho de que el ocio es en sí mismo un ejercicio práctico o una actividad a la que se dedica el hombre (sabio) por el placer de hacerlo, porque su único propósito es el de servir a la humanidad (o a la nación de todos los hombres en tiempo y en espacio). Por ello, la contemplación tiene que ver, como plantea Sloterdijk, no con el trabajo sobre el concepto, sino con sus vacaciones, vagancia o vagabundeo por la gran panorámica, esto es, el vuelo libre de las almas: el pensador, el contemplador, el filósofo, dice Sloterdijk, se parece más a un veraneante que a un currante, y pensar resulta, entonces, "una experiencia parecida a un profundo alivio de tensiones para el intelecto. [...] El pensamiento filosófico es, antes que nada, una técnica de felicidad [o jovialidad], sólo después surgen los problemas" (Sloterdijk, 2003, p. 62).

Conforme a esta postura, la consabida y convencional perspectiva peyorativa sobre el ocio de la cristiandad, no solo conlleva una profunda paradoja, sino que parece condenar, poco a poco, la naturaleza del hombre que ocupado de sí decide sobre su propio modo de ser (Foucault, 1987, 2002). La paradoja evidente es que la denominada, por ejemplo, por el mismo Pieper (2003), vida intelectual, que requiere una entrega absoluta en tiempo y cuerpo, así como su exaltación en cuanto modo "ideal" de vida, comporta el oficio del ocioso a través del cual los clérigos, escolásticos, monacales se dedicaron a escribir en contra de lo que vino a llamarse pereza. Bien se sabe que el ocio referido a la holgazanería es, en la tradición religiosa, bastante contingente, por lo que el sentido real de esta ociosidad es más cercano a la desidia que al otium, esto es, al desgano que impide a los hombres realizar las tareas espirituales (tales como rezar). Por ello, el ocioso suele ser aquel que no hace nada en el sentido de no seguir las indicaciones comportamentales exigidas para ser un buen cristiano. Con lo cual la ociosidad alcanza, entonces, la categoría de desgracia, al punto que en el lenguaje ordinario se lo toma por insulto.

No hacer nada, no obstante, parece imposible, de modo que la ociosidad se precisa un poco si se refiere a no hacer nada obligatorio (o a hacer algo por gusto, como se sabe de sobra en los estudios sobre ocio). Así, deben seguirse nuevas huellas de la asimétrica panorámica del ocio durante la Edad Media (de la libertad de Duns Scoto a la locura de Erasmo, por ejemplo). Por su parte, en la 
vida moderna, industrializada, en la que el desocupado es propiamente un desempleado que puede morir de hambre en cualquier esquina, y en la que millonarios se jactan diariamente de lo que tienen y pueden hacer con lo que tienen, la concepción y experiencia de la ociosidad adquiere un matiz completamente nuevo sobre el que es necesario reedificar las nociones del hacer o no hacer nada con obligación. En este horizonte, el ocio reclama un análisis etológico de la obligatoriedad y del trabajo, que se enriquezca con los labor studies (Offe, 1984), tanto como con la economía política (Rojek, Shaw y Veal, 2006). De esta manera, se evidenciará que entre la ostentosa clase ociosa de Thorstein Veblen (2011) y lo que medio siglo después en Norteamérica empezaría a denominarse la industria del ocio (o industrias culturales en el lenguaje de Adorno y Horkheimer), sucedieron drásticos cambios de perspectiva respecto de lo que la ociosidad es, permite y constituye en relación con el trabajo asalariado.

De este modo, lo que ahora puede esperarse no es una historia del ocio en la que se afirme, como ya se ha hecho (Sue, 1987), que cada época y sociedad tiene un sentido específico de la palabra, ni, de otro modo, que aquello que es denominado ocio varía según el tiempo y la geografía. Realmente no es así de simple. ¿Por qué Sloterdijk (2012, pp. 244-245) identifica el derecho a la pereza (que sin embargo no remite directamente a Lafarge) a la diferenciación no vertical de las "identidades", cuando la pereza pasa de ser entendida como una "carencia corregible" a un "fenómeno valioso"? ¿Acaso la ociosidad es llanamente el opuesto complementario, o la negación moderna, del ejercicio permanente, de la capacidad autoplástica del hombre? ¿No podrían los ociosos ser en algún sentido ejercitantes (como se ve en Séneca)? ¿No es el ejercicio espiritual, la antropotécnica como tal, un puro otium? 0, siguiendo la argumentación aristotélica, si la scholé es el principio de todas las cosas, ¿no viene a ser como la condición de posibilidad de la antropotécnica?

Estas no son preguntas que pretendemos resolver en este ensayo, si bien se avanza en una dirección en la que las respuestas se elaboran casi solas. El presente texto tiene por propósito central argumentar en favor de las formas de vivir ociosas basadas en ejercicios prácticos de ociosidad. El texto plantea la importancia de reconocer esta ejercitación en cuanto modo de alcanzar no una sociedad, sino una edad de ocio (en el sentido de scholé, de acuerdo con Illich). Para ello, se contempla en primera instancia la antropología filosófica de Peter Sloterdijk. En seguida, el texto contrasta esta tesis con los planteamientos de Foucault respecto a las prácticas de sí. Finalmente, a partir de este análisis, se revisa el concepto de ocio, estableciendo una idea según la cual ser ocioso no significa simplemente no-hacer-nada, en cuanto que se trata más bien de una actitud vital absolutamente virtuosa, generosa y creativa que se adquiere conforme un cuidadoso ejercicio de la libertad y de la espontaneidad. Esperamos que esta perspectiva, pues, permita concepciones diversas sobre el ocio que vayan más allá de la industria o, mejor, de los servicios, así como de la práctica del arte y del hacer la fiesta, y también permita comprender que solo es ociosa una práctica en cuanto contribuye a la autoproducción del hombre.

\section{EJERCITARSE, EXPERIMENTARSE, LLEGAR A SER SIENDO}

Sin pretensiones reduccionistas, la antropología filosófica de Peter Sloterdijk puede resumirse del siguiente modo: el hombre se produce a sí mismo viviendo su vida en distintas formas de ejercicio; esto es, siguiendo a Nietzsche, el hombre es el animal ascético por excelencia, quien al ejercitarse o entrenarse consigue autoproducirse, crear su propia forma de vivir. Sin duda, y como el mismo Sloterdijk lo afirma, esta tesis tiene como fuente la secularidad moderna según la cual el hombre, sobre todo en relación con los asuntos públicos, con la política, no cumple un destino, sino que lo forja. Y, más aún, bebe de la eterna fuente que son los griegos para Occidente, en cuanto que fueron ellos quienes descubrieron - y afianzaron - el sentido artístico de la existencia humana (versión absolutamente nietzscheana).

Sin embargo, la originalidad de Sloterdijk está dada por el hecho de que esta fabricación o invención de la propia vida, no se logra necesariamente por la razón (inclinada hacia el bien), ni por el trabajo (en cuanto que mera ocupación retribuida). El centro de la tesis de Sloterdijk es el ejercicio, el cual entiende como "cualquier operación mediante la cual se obtiene o se mejora la cualificación del que actúa para la siguiente ejecución de la misma operación" (2012, p. 17). Por ello, se sobreentiende aquí la influencia del último Foucault, al punto que puede 
ciertamente considerase el estudio de Sloterdijk como la continuación de los esfuerzos del francés (cf. CastroGómez, 2012).

Aunque en primera instancia y teniendo como referente al deportista moderno, esta definición podría hacernos pensar que el ejercicio conlleva al automatismo absoluto, pero no hay nada más lejos de la realidad. De hecho, se trata de todo lo contrario: uno no afianza ciertos movimientos con el único fin de reaccionar luego, la ejercitación exige el uso reiterativo de, o el esfuerzo en conseguir algo que se obtiene únicamente por la misma ejercitación. Es lo que Sloterdijk denomina el poder de la repetición contra la repetición, lo cual podríamos precisar así: a través de la repetición de lo que hacemos podemos decir que somos eso que hacemos. El ejercicio al que se refiere Sloterdijk conviene en la inversión del extrañamiento de la existencia producida por la inercia de la repetición "inconsciente", del hábito o del amaestramiento. Pero como no se trata de repetir cualquier cosa, ni de repetirla sin más, la cuestión está en qué es aquello en lo que uno se ejercita y por qué.

La tesis de Sloterdijk no solo muestra que el hombre es un animal que se ve enfrentado a conducir su propia vida (como la antropología filosófica lo ha replicado sin descanso), sino que esta conducción, además de ser específicamente la "naturaleza humana", exige la conversión de aquello cuanto lo hace ser lo que es en tanto que animal de pasiones o afectos, costumbres e ideas caóticas. Estas, dice Sloterdijk, son como programas que marchan por sí mismos y hacen que un hombre cualquiera viva de cierto modo y no de otro. Por ello, el punto de la ejercitación en cuanto que antropotécnica, consiste en saberse preso de tales programas y revertirlos, alterarlos, afectarlos en pro de una autoprogramación práctica. Se trata de que el hombre, siendo repetido en su pasividad, se convierta en un ser activo que se repite él mismo, que se ejercita por ser él mismo.

La tesis se inspira en la última frase de un soneto de Rilke denominado Torso arcaico de Apolo, que Sloterdijk adopta como título de su libro, y la cual está cargada de una espectacular fuerza creadora: "Has de cambiar tu vida". Ahora bien, cambiar la propia vida, de acuerdo con la tesis de Sloterdijk, precisa tres transformaciones especiales relacionadas con la inercia de la vida humana: (I) la inercia de las pasiones, que arrastran al hombre a distintas clases de sufrimiento y al descontrol;
(II) la inercia de las costumbres que lo poseen sin que ni siquiera se percate de ello; y, (III) finalmente, la inercia de las representaciones confusas que pueblan su psique y lo flagelan por su propia incomprensión.

Cambiar la propia vida sería, entonces, ir al otro lado y no ser dominado, sino dominador de las pasiones, dejar de ser poseído y poseer sus propias costumbres, y en vez de vivir conforme pensamientos confusos, desarrollar sus propias ideas (lógicamente estables). No se trata, como se ve, únicamente de pensar por sí mismo, expresión que desde Kant da vueltas en el espectro del llegar a ser quien uno mismo quiere ser, o alcanzar la mayoría de edad. La tesis de Sloterdijk sobre la antropotécnica sugiere un esfuerzo activo, una serie de acciones concretas, la dedicación práctica sobre sí, el experimentar con uno mismo en cuanto "individuo", aunque esto conlleve riesgos.

La toma de conciencia de la individualidad es el individualismo auténtico [...] el individualismo [que] surge en el momento en el que los hombres se convierten ellos mismos en autores de sus propias descripciones, esto es, cuando empiezan a reclamar los derechos de autor respecto a sus propias historias y opiniones [...] Cuando decimos "individuo", se quiere decir un sujeto involucrado en la aventura de su propia autoconservación, un sujeto que quiere determinar en términos experimentales qué tipo de vida es la mejor para él. [No obstante] el alma que realiza experimentos consigo misma, que se descompone hasta llegar a sus últimas partículas, se descubre a sí misma como una nada realmente existente, una especie de monocromía, una superficie indiferente [...] esto es lo que es el yo ante el yo: un simple fondo sin figura, una pantalla sin texto. (Sloterdijk, 2003, pp. 50, 32, 34, 42, 43).

En este sentido, la experimentación con uno mismo puede, o bien orientarse en el sinsentido de las siempre pululantes ensoñaciones vagas del consumismo zombi, por el cual los individuos no son más que "egoístas refinados religiosamente embelesados por lo existente" (Sloterdijk, 2003, p. 46), o bien orientarse por la experiencia de la liberación. En últimas, dice Sloterdijk:

Con esto hay que contar siempre: existe en realidad una fuerza, alimentada por tensiones puramente internas, que tiende a liberarse, a estallar y a buscar la transformación; en la mayoría de los casos, irrumpe hacia arriba en forma de fiebre religiosa o de embriaguez bélica. Pero cuando no se presenta una posibilidad mejor, este mismo material energético puede canalizarse en una política 
prerrevolucionaria [...] Los hombres son animales que advienen, animales de llegada, animales experimentales, ellos están siempre de camino. (2003, pp. 85, 89).

La antropotécnica, en este sentido, implica a la experimentación como un ejercicio en sí, el cual, articulado con otros ejercicios y rutinas, configura una vida ejercitante o el automodelamiento conseguido mediante el ejercicio. La ascesis nietzscheana, tal y como Sloterdijk la emplea, nos permite así comprender que no se trata de ninguna clase de penitencia, como el cristianismo aún hoy lo expone, sino como el arte de superación y fortalecimiento de la pasividad respecto del hecho de vivir la propia vida.

El enlace entre la tesis de Sloterdijk y la ociosidad, pese a sus breves comentarios contra la perez $^{3}$, radica pues en la relación que establece con la forma de vivir de la Grecia del siglo v a. n. e. (y sobre todo respecto a los cínicos, "los filósofos del ascetismo total"). Según indica, fue allí cuando brotó la filosofía como atletismo, como un esfuerzo prolongado para forjarse a sí mismo en la virtud o, lo que vendría a ser lo mismo, como la ocupación en las tareas para transformarse, para vivir una vida ética por excelencia.

Cambiar su vida significaría ahora configurar, mediante actividades internas, un sujeto que debe ser superior a su vida pasional, a su vida de hábitos, a su vida de representaciones. Según esto, se convertiría en un sujeto así quien participe en un programa de despasivización de sí mismo y pase, de un estado donde era meramente un ser moldeado al otro lado, al lado de los moldeadores. Todo ese complejo llamado ética surgiría del gesto de conversión a la propia capacitación. La conversión no sería un tránsito de un sistema de creencias a otro. La conversión originaria acontecería como la salida de un modo de existencia pasivo y la entrada en un modo que irradia actividad. (Sloterdijk, 2012, pp. 253-254).

3 "Ya las instituciones de la vida cotidiana reafirman que el comienzo de las virtudes no es la ociosidad. Los monjes cristianos veían en la pereza la madre de la desesperación, acompañada por el resto de sus hijas, carentes de todo atractivo: la divagación, la verborrea, la curiosidad malsana, el desenfreno y la versatilidad. Es la línea que hace todos los días la que forma al artista, la renuncia cotidiana al asceta, el trato diario con las necesidades de poder de otros hombres al diplomático y el gozo diario en la estimulación de los niños al maestro" (Sloterdijk, 2012, pp. 409-410).

\section{LA EXISTENCIA COMO OBRA DE ARTE}

Ahora bien, entre las últimas entrevistas y/o diálogos que Foucault mantuvo antes de su muerte, existe una que ha llegado a ser emblemática, debido a que en ella pronunció una frase que se ha convertido en una suerte de consigna. Foucault es interrogado a propósito de sus investigaciones sobre el periodo grecorromano que supusieron un cambio en la dinámica de sus anteriores escritos y produjeron no pocas conmociones debido al análisis moral que contenían. Esto último, en particular, empezó a adquirir una singular importancia, y en relación con el tema de este escrito, las palabras de Foucault a propósito, resuenan retrospectivamente como una explicación (arqueológica, genealógica) de la antropotécnica de Sloterdijk.

Con el cristianismo se produjo un lento, gradual desplazamiento en relación a la moralidad de la antigüedad, que era esencialmente una práctica, un estilo de libertad. Por supuesto también ha habido ciertas normas de conducta, que gobernaban el comportamiento de cada individuo. Pero el deseo de ser un sujeto de moral, y la búsqueda de una ética de la existencia, eran en la antigüedad solamente un intento de afirmar la propia libertad y dar a la propia vida una cierta forma, en la que se podía reconocer uno mismo, ser reconocido por otros, y que aún la posteridad podría tomar como ejemplo. Esta elaboración de la propia vida como una obra de arte personal, si bien obedecía ciertos cánones colectivos, estaba en el centro, pienso, de la experiencia moral, la voluntad de moralidad en la antigüedad; mientras que en el cristianismo, con el texto religioso, la idea de la voluntad de dios, el principio de obediencia, la moralidad tomó gradualmente la forma de un código de normas (sólo ciertas prácticas ascéticas estaban más relacionadas con el ejercicio de la libertad individual). Desde la antigüedad al cristianismo, pasamos de una moralidad que era esencialmente la búsqueda de una ética personal, a una moralidad como la obediencia a un sistema de normas. Y si me interesé en la antigüedad fue porque, por todo un cúmulo de razones, la idea de moralidad como obediencia a un código de normas está desapareciendo, ya ha desaparecido. A esta ausencia de moralidad corresponde, debe corresponder, la búsqueda de una estética de la existencia. (Foucault, 2009, p. 134. Cursivas nuestras).

La estética de la existencia, la creación de la propia forma de vivir, es, entonces, llevada del asunto moral -en el que las reflexiones se subsumen la mayoría de 
las veces a la relación del hombre con el hombre- a un plano de discusión onto-etológico, en el que el ser del hombre no se analiza en función de la sociedad en la que vive, sino en función de la investigación sobre su propia naturaleza. En esta discusión, como veremos, el ocio resalta como el estado vital de lo existente y, particularmente en relación con el hombre, como el estado en que este crea su existencia. Por ello, todos los análisis respecto del trabajo, incluidos los marxianos, terminan desembocando en la parálisis, la detención de la capacidad creadora, el automatismo y el esclavismo. No es raro, por ello, que haya sido el yerno de Marx, Lafargue (2004), quien hubiera escrito el Derecho a la pereza como una refutación al derecho al trabajo de $1848^{4}$. El punto ahora consiste en que la vida puede adoptarse como una obra de arte de la que uno mismo es el creador.

Pero podemos también caracterizar esta idea, para justificarla, en quien es considerado el pensador más importante de la libertad individual en Occidente en cuanto que ejercicio político; quien, a pesar de estar vinculado a la criticadísima racionalidad gubernamental liberal y utilitarista, logró - como lo expone Berlin, en clave de su propia individualidad-, distanciarse de la administración total de la vida en pro de la libertad y la tolerancia de pensamiento y acción ${ }^{5}$. Sigamos, pues, a John Stuart Mill en lo siguiente:

Nadie piensa que la excelencia en la conducta humana consista en que la gente no haga más que copiarse unos a otros. Nadie sostiene que en la manera como las gentes vivan y rijan sus negocios no deba influir para nada su propio juicio o su propio carácter individual. Por otra parte, sería absurdo pretender que la gente viva como si nada se hubiera

4 Lafargue no escribe ambigüedades: "El proletariado sube arrastrándose desde hace un siglo por el duro Calvario del dolor, igual que Cristo, la dolorosa personificación de la antigua esclavitud. Hace ya un siglo que el trabajo forzoso rompe sus huesos, atormenta su carne y atenaza sus nervios; desde hace un siglo, el hambre desgarra sus vísceras y alucina su cerebro... ¡Oh Pereza, compadécete de nuestra miseria! ¡Madre de las artes y de las nobles virtudes, oh Pereza, se tú el bálsamo de las angustias humanas!" (2004, p. 134).

5 En la conferencia del Robert Waley Cohen Memorial, pronunciada en Londres el 2 de diciembre de 1959, titulada "John Stuart Mill y los fines de la vida", la cual sirve de prólogo a la versión de Alianza Editorial de Sobre la Libertad, Isaiah Berlin anota sobre Mill: "Para él, el hombre se diferencia de los animales no tanto por ser poseedor de entendimiento o inventor de instrumentos y métodos, como por tener capacidad de elección; por elegir y no ser elegido; por ser jinete y no cabalgadura; por ser buscador de fines, fines que cada uno persigue a su manera y no únicamente de medios" (2007, p. 15). conocido en el mundo antes de su venida a él; como si en la experiencia no hubiera nada para mostrar que una manera de vivir es preferible a otra. Nadie niega que la juventud deba ser instruida y educada de manera que conozca y utilice los resultados obtenidos por la experiencia humana. Pero el privilegio y la propia madurez de sus facultades consiste en utilizar e interpretar la experiencia a su manera. A él corresponde determinar lo que, de la experiencia recogida, es aplicable a sus circunstancias y carácter. [...] Entre las obras del hombre, en cuyo perfeccionamiento y embellecimiento se emplea legítimamente la vida humana, la primera en importancia es, seguramente, el hombre mismo. [...] La naturaleza humana no es una máquina que se construye según un modelo y dispuesta a hacer exactamente el trabajo que le sea prescrito, sino un árbol que necesita crecer y desarrollarse por todos lados, según las tendencias de sus fuerzas interiores, que hacen de él una cosa viva. (2007, pp. 129-131).

Para Mill, las tradiciones y hábitos están estrechamente ligados a las experiencias que han tenido las personas, son un producto de estas experiencias, lo que las hace contingentes en cuanto cada individuo - por sí mismo y por ser cada circunstancia diferente- experimenta de forma distinta. Las experiencias pasadas, sin duda, enseñan y sirven de soporte a nuestras presentes formas de vivir; pero pueden ser cambiadas en cuanto plausiblemente fueron mal interpretadas, o bien, inadecuadas para aplicar en otros momentos. Y, más aún, incluso cuando tales tradiciones y hábitos pueden de hecho servir a los fines de la vida presente, seguirlos sin cuestionarlos, sin pensar detenidamente en ellos, "no educa ni desarrolla [...] las cualidades que son el arbitrio distintivo del ser humano" (Mill, 2007, p. 130). Por tanto, estar abierto al hecho de poder y deber cambiar las formas de vivir, si seguimos a John Stuart Mill, es en sí mismo un acto político-ético ${ }^{6}$.

6 Priorizamos ahora estos planteamiento sacrificando la posible objeción de que Mill, en el texto citado, de hecho justifica la imposición de la sociedad occidental en las sociedades amerindias y orientales con base en el statu quo, lo cual lo pone - para nuestras circunstancias actuales - en clara contradicción. Tal análisis crítico a Mill, importantísimo sin duda, no obstante, puede alivianarse aceptando que para él verdaderamente era imposible salir de su propio momento histórico. Así que la advertencia no deslegitima ni pervierte la afirmación de la libertad (individual), la tolerancia y el cambio de las pasadas maneras de vivir. 
Ahora bien, en los términos en que Foucault aborda esta transformación, la libertad individual juega un papel fácilmente hermanable con el planteamiento de Mill. Las tradiciones y hábitos funcionan como un "código de normas" que se imponen a las nuevas generaciones; son normas de conducta, una moralidad que gobierna el comportamiento de cada individuo (cf. Foucault; 2009 , p. 134). La moralidad subsume, es una forma de sujetar o de hacer entrar en cierto orden. Por ello, se responde contra ella ampliando el espacio de libertad, "entendido como espacio de libertad concreta, de posible transformación" (Foucault, 2009, p. 122). En este sentido, el concepto de hombre libre se adopta como base del comportamiento propiamente humano, el cual puede comprenderse como un ejercicio de elección pero, sobre todo, de invención. De este modo, como afirmara Foucault, "la historia sirve para mostrar que lo-que-es no ha sido siempre así; o sea, que lo que nos parece más evidente está siempre formado por la confluencia de encuentros y posibilidades, en el transcurso de una historia precaria y frágil" (2009, p. 122) ${ }^{7}$.

En este sentido, la existencia como un movimiento que se orienta en función de lo que nosotros mismos creamos no solo afirma la contingencia de lo que nos pasa, sino la transformación de lo que venimos siendo acorde con la práctica de liberación de las tradiciones o de la moral. Siguiendo a Deleuze, "se trata de la constitución de modos de existencia o, como decía Nietzsche, de posibilidades vitales. No la existencia como sujeto, sino como obra de arte" (Deleuze, 1999, p. 82). Un proceso mediante el cual el hecho de estar viviendo de una manera, el hecho de ser socio-históricamente obligado a vivir de cierta manera, sucumbe ante la transfiguración de la vida singular y adquiere otra sensibilidad (otra carne).

Esta es la ética en cuanto la relación con uno mismo al actuar. El ejercicio de su propia transformación. Foucault llegó a ella procurando la determinación de

7 La relación entre Mill, Sloterdijk y Foucault no es extraña en este punto, siempre que se asimile su análisis sobre Kant, la modernidad y Baudelaire: "La modernidad baudelaireana es un ejercicio en el que la extrema atención a lo real se confronta con la práctica de una libertad que al mismo tiempo respeta eso real y lo viola. [...] La actitud voluntaria de modernidad está ligada a un indispensable ascetismo, ser moderno no es aceptarse a sí mismo tal como se es en el flujo de los momentos que pasan; es tomarse a sí mismo como objeto de una elaboración compleja y dura [...] Tal modernidad no libera al hombre en su ser propio, le obliga a la tarea de elaborarse a sí mismo" (Foucault, 2015, pp. 36-37. Cursivas nuestras). la sustancia ética, preguntándose por qué un individuo en un momento y en una sociedad dada actúa de cierto modo y no de otro respecto de lo que concibe como una conducta apropiada aun cuando esta le cueste la vida. No se trata solo de códigos y de obediencia, es decir, de una conducta sumisa. El trabajo ético, como a veces lo denominó Foucault, expone el modo por el cual el hombre ejerce un poder sobre sí, esto es, modifica sus propias acciones presentes y futuras. De este modo, se habla de un ejercicio práctico y no únicamente "meditativo".

Como dice Foucault, la constitución de uno como sujeto (sujeto moral) no se puede lograr "sin una 'ascética' o 'prácticas de sí' que lo apoyen" (2005, p. 29). Sin estas prácticas no habría una contundente transformación del propio modo de ser, ya que el hombre, al ser un existente, no solo es un ser-que-piensa, es esencialmente un ser activo, un ser que se mueve en el mundo, un existente que tiene un modo de vivir particular. De Foucault a Sloterdijk, de la conducta ética a la antropotécnica, entonces, "el acento cae sobre las formas de relacionarse consigo mismo, sobre los procedimientos y las técnicas mediante las cuales se las elabora, sobre los ejercicios mediante los cuales uno se da a sí mismo como objeto de conocimiento y sobre las prácticas que permiten transformar su propio modo de ser" (Foucault, 2005, p. 31). Y, por ello, la diferencia (vertical) entre virtuosos y no virtuosos, la cual es para Sloterdijk la gran revolución del ascetismo, consiste en lo que Séneca denominaba ocio activo:

Así como es muy poco loable apetecer cosas materiales sin afán alguno de virtudes y sin cultivo del talento propio, y realizar las tareas sin más (pues son cosas que deben ir unidas y mezcladas), igualmente es un bien imperfecto y endeble la virtud malgastada en un ocio sin actividad, sin mostrar nunca lo que ha aprendido. [...] ¿Con qué ánimo se retira el sabio al ocio? Con la convicción de que también entonces va a hacer cosas por las cuales será útil a la posteridad. (Séneca, 2010, pp. 160-161. Cursivas nuestras).

En este sentido, y a pesar del distanciamiento que según Sloterdijk existe entre las ascesis antiguas y la moderna, se nos presenta una tarea ineludible: "Tenemos que transformarnos a nosotros mismos, modificándonos técnicamente, si es que queremos salvar la vida humana sobre el planeta. [Transformarnos apostando] por una autoselección de las conductas y por unos medios de 
autocontención" (Castro-Gómez, 2012, p. 72). Pero, como decía Russell (1953), mientras el hombre común siga encadenado al "trabajo asalariado", de acuerdo al cual se debe dedicar la mayor parte del tiempo vital en la laboriosidad, pensar siquiera en la necesidad de esta trasformación le será imposible; así que es el ocio, como otium, el único que permite la realización de esta tarea.

\section{LLEGAR A SER OCIOSO. ARISTÓTELES Y EL PLACER}

Entre los estudios sobre el ocio, de entre los griegos clásicos se remite regularmente a una frase del libro $\mathrm{x}$ de la Ética a Nicómaco de Aristóteles, en la que sugiere, como muestra Pieper (2003), que se trabaja (o se está no-ocioso) para tener (o hacer el) ocio. Esta referencia, no obstante, debe ser ampliada para comprender mejor a qué se refiere Aristóteles. El libro x empieza analizando el placer, o el hecho de hallar gusto en lo que uno hace, el hecho de gozar con lo que se hace en cuanto que gozar es la actividad misma del placer.

Aristóteles discute distintos argumentos sobre la naturaleza del placer (si es el bien en general, o un bien cualquiera o únicamente una cualidad) y su relación con el dolor, mas afirma que el placer es un todo entero y completo (como lo es por ejemplo un templo terminado) de modo que, aunque pueda aumentar o disminuir, no se trata de algo parcial que va a complementar otra cosa. Aristóteles continúa su análisis planteando que si bien el placer es en sí mismo, está íntimamente ligado con la actividad, ya que son las actividades las que nos causan placer y el placer, a su vez, el que las intensifica.

De esto se sigue, según Aristóteles, que cada actividad tiene un placer distinto, así como lo tiene cada "especie" de ser animado según su actividad o función: es claro que así como el placer de escuchar una flauta es distinto del de leer un libro antiguo, los asnos prefieren el pasto al oro (ejemplo que Aristóteles toma de Heráclito). Pero, si es así, ¿cuál es entonces el placer propio del hombre? Como nos es evidente, no todos los hombres hacen lo mismo, ni tampoco lo encuentran igual de placentero. Entonces, ¿cuáles podrían ser la actividad y el placer propio del hombre en cuanto tal? La respuesta que el estagirita da a estas preguntas, es la clave de lo que nos interesa tratar aquí. Aristóteles construye su argumento con base en la dicotomía que ha orientado todo el texto: del mismo modo en que al hombre enfermo lo que es dulce no le parece, aquello que causa placer al hombre corrompido o no virtuoso no es digno de ser considerado como el placer propio del hombre. Por el contrario, $l a$ impresión verdadera que se ha de considerar es la del hombre bueno o virtuoso, es decir, "serán placeres los que se le parezcan a él, y agradable aquello en lo que él se deleite" (1176a; en la edición utilizada: 2009, p. 164).

Recuérdese que para Aristóteles el fin de todo lo humano es la felicidad (la plenitud traducirán algunos), en cuanto esta es una actividad que resulta deseable por sí misma en la medida en que se basta a sí misma, esto es, en cuanto que no se desea para otra cosa y en cuanto que no necesita de nada:

Ahora bien, se eligen por sí mismas aquellas actividades en que no se busca nada fuera de la misma actividad. Tales parecen ser las acciones virtuosas, pues el hacer lo que es honesto y bueno, pertenece al número de las cosas deseables por sí mismas. (Ética a Nicómaco, 1176b).

El placer propiamente humano, entonces, es el que causa la acción virtuosa, la actividad que es buena en sí misma, la felicidad en cuanto que actividad contemplativa. Por ello, Aristóteles opone los "juegos" (de los esclavos) a la felicidad, ya que estos son meras diversiones y la diversión es una especie de descanso, pausa entre el trabajo, debido a que ningún hombre puede trabajar de continuo. Los juegos causan placer a los esclavos, "pero de la felicidad nadie hace partícipe al esclavo, a no ser que le atribuya también vida humana propiamente dicha. Porque la felicidad no está en tales ocupaciones, sino en las actividades conforme a la virtud" (Politeia, 1177a).

En este sentido, la felicidad es la actividad del hombre libre, que puede (y por derecho lo hace) dedicarse a practicar la contemplación, la actividad que se refiere a la sabiduría y, por tanto, la más virtuosa en cuanto esta es la que le es primariamente al hombre bueno: la vida conforme a la mente (nous Bios), o a la divinidad. Por supuesto, como ya Platón lo había señalado, el hombre libre puede dedicarse a las actividades contemplativas o a las actividades prácticas, relacionadas con la política y con la guerra. Y, no obstante, como lo señalará Séneca (2010) después, solo en la vida contemplativa, opuesta a la vida política (o vida activa), el hombre encontrará aquello que lo hace ser quien es. 
Aristóteles pensaba que la política y la guerra eran actividades que carecían de ocio puesto que no se eligen por sí mismas sino por los bienes (poderes, honores, etc.) que producen; de modo que

Si entre las acciones virtuosas son las primeras en gloria y grandeza las políticas y guerreras, y éstas carecen de ocio y aspiran a algún fin y no se eligen por sí mismas, mientras que la actividad de la mente, que es contemplativa, parece superior en seriedad, y no aspira a ningún fin distinto de sí misma, y tiene su placer propio (que aumenta la actividad), y la autarquía, el ocio y la ausencia de fatiga que pueden darse en el hombre y todas las demás cosas que se atribuyen al hombre dichoso parecen ser evidentemente las de esta actividad, ella será la perfecta felicidad del hombre, si ocupa el espacio entero de su vida, porque en la felicidad no hay nada incompleto. (Ética a Nicómaco, 1177b; en la edición utilizada: 2009, p. 166).

De este modo, cuando comprendemos que la vida contemplativa es en sí misma la vida ociosa, conforme la argumentación anterior, podemos afirmar que la esencia del hombre es ser ocioso. Pero para evitar perspicaces objeciones, es necesario aseverar, por un lado, que Séneca no era del todo aristotélico (si bien su filosofía "ecléctica" tiene sin duda alguna enlaces con el pensamiento del estagirita) y, por otro, que otium, en este sentido, tiene muy poco que ver con el ocio cristiano. El punto es que esta noción no es, propiamente dicha, un axioma filosófico, o no lo es hasta que Séneca lo conceptualiza en sus epístolas. Entre los griegos clásicos, la expresión skolé, sjolé o scholé ( $\sigma \chi 0 \lambda \eta ́)$ —como se muestra en Aristóteles y afirman Pieper (2003) y Pérez de Ayala (1975), por ejemplo- es una noción común de lo que implica dedicarse al estudio, a los ejercicios "teóricos", a la práctica a través de la cual se adquiere la virtud, a la escritura y similares, esto es, el ocio es lo que hace hombre el hombre. Valga entonces traer a colación la idea de Séneca, según la cual "de hecho, no hay contemplación sin acción” (2010, p. 159) ${ }^{8}$.

8 Sobre la supuesta oposición entre las tres clases de vida, la del placer (apolaustikós bíos), la de la acción (praktikós bíos) y la de la contemplación (theorstikos bíos), Séneca dirá en su texto sobre el ocio: "Ante todo, dejemos a un lado la polémica, dejemos a un lado el odio implacable que hemos declarado a los partidarios de las doctrinas rivales, y veamos cómo todas estas clases de vida, bajo distintos pretexto, vienen a parar a lo mismo: ni aquel que aprueba el placer crece de contemplación, ni aquel que se entrega a la contemplación carece de
En este sentido, ser ocioso es hacer lo que se hace por puro placer, por mor de lo que se hace como tal o, como decía Illich (2006), sin propósito ulterior. Por ello, Pieper (2003) consideraba que el arte-por-el-arte había sido un ejemplo de la vida ociosa; y no debe extrañarnos entonces que los artistas que jugaron (y juegan) como activistas políticos hayan concebido tal expresión como un desperdicio de creatividad. Esta actitud es más que mal vista, despreciada, en una sociedad capitalista, ya que, como afirmaba Russell, "la noción de que las actividades deseables son aquellas que producen beneficio económico lo ha puesto todo patas arriba" (1953, p. 33). Siempre hay un muy buen argumento, sumamente convincente, para pensar que actuar sin que se reciba algo a cambio, sin que se gane algo, es una actividad insulsa y perdida. Pero en el fondo, el problema de la ociosidad, o de la pereza, si se quiere, es como decía Lafargue: ¿qué hacer para matar el tiempo que nos mata? La cuestión, por tanto, no solo es de acciones o quehaceres, es sobre todo temporal o, mejor, vital. La pregunta, en otros términos, podría ser entonces: ¿cómo pasamos el tiempo?, ¿qué hacemos con nuestro tiempo?, o bien, ¿qué hacemos con nuestras vidas?

\section{SUSCITACIÓN FINAL}

En conclusión, una indicación existencial del ser ocioso está en el autocuestionamiento sobre lo que se hace por sí y para sí en cuanto que ser vivo. No en función de lo que puede obtenerse, como prestigio, dinero o mujeres, sino en cuanto se realiza una forma de ser, un modo particular de vivir. Diríase con Kant que se trata de tomarse como un fin en sí mismo. 0, según la lectura foucaultiana de Kant, "el trabajo de nosotros mismos sobre nosotros mismos en nuestra condición de seres libres" (Foucault, 2015, p. 48). Y, no obstante, más allá de lo que pueda significar el hacerse cargo de sí en el mundo, la ociosidad trata principalmente de un tipo particular de ejercitación: el estudio, la lectura, la escritura, la meditación, la conversación, los viajes, el arte... en una palabra, cultivarse (Russell, 1953). De este modo, más que una contradicción, en nuestro uso de Sloterdijk sobre la antropotécnica, lo único que hay que reprocharle a este autor es el empleo de la ociosidad y la pereza como su opuesto.

placer, ni aquel cuya vida está destinada a la acción [política] carece de contemplación" (2010, pp. 163, 164). 
Sin embargo, no es solo una cuestión de palabras. Nuestra tesis es que el sentido de la ociosidad - expresada en Aristóteles así como en Séneca, en Pieper así como en Lafargue, en Russell o en Ramón Pérez de Ayala, a pesar de las diferencias que se pueden establecer entre estos autores- se nos aproxima conforme el análisis de la autoproducción del hombre a través del ejercicio o, en términos de Foucault, de las prácticas de sí. Ser ocioso es una forma de vivir, un modo de ser que se adquiere en el momento en el que se dedica la vida, el tiempo vital, a actividades de liberación de las obligaciones, de la sumisión incomprensible, del automatismo, y se procura uno el cultivo personal. Lo que, en suma, significa que la ociosidad es una actitud vital absolutamente virtuosa, generosa y creativa que se adquiere conforme un cuidadoso ejercicio de la libertad y de la espontaneidad.

\section{REFERENCIAS}

Aristóteles (1989). Politeia (La Política, traducción de Manuel Briceño Jáuregui). Bogotá: Instituto Caro y Cuervo.

Aristóteles (2009). Ética a Nicómaco (Edición bilingüe de Julián Marías y María Araujo). Madrid: Centro de Estudios Políticos Constitucionales.

Berlín, I. (2007). John Stuart Mill y los fines de la vida. Prólogo de Sobre la Libertad. Madrid: Alianza Editorial.

Castro-Gómez, S. (2012). Sobre el concepto de antropotécnica en Peter Sloterdijk. Revista de Estudios Sociales, 43, 63-73

Deleuze, G. (1999). Conversaciones, 1972-1990. Madrid: Pre-Textos.

Deleuze, G., y Parnet, C. (2004). Diálogos. Madrid: Pretextos.

Deleuze, G., y Guattari, F. (1997). Mil Mesetas. Madrid: PreTextos.

Foucault, M. (1987). La inquietud de sí. Historia de la sexualidad 3. México: Siglo xxI Editores.
Foucault, M. (2002). La hermenéutica del sujeto. Curso en el Collége de France (1981-1982). Buenos Aires: Fondo de Cultura Económica.

Foucault, M. (2005). El uso de los placeres. Historia de la sexualidad 2. México: Siglo xxI Editores.

Foucault, M. (2009). El yo minimalista y otras conversaciones. Buenos Aires: La Marca Editora.

Foucault, M. (2015). ¿Qué es la Ilustración? Medellín: Editorial Universidad de Antioquia.

Gómez de Silva, G. (2006). Breve diccionario etimológico de la lengua española. México: Fondo de la Cultura Económica.

Illich, I. (2006). Obras reunidas (Vol. 1). México: Fondo de Cultura Económica.

Lafargue, P. (2004). El derecho a la pereza. Buenos Aires: Longseller.

Mill, J. S. (2007). Sobre la Libertad. Madrid: Alianza Editorial.

Offe, C. (1984). La sociedad del trabajo. Problemas estructurales y perspectivas de futuro. Madrid: Alianza Editorial.

Pérez de Ayala, R. (1975). Viaje entretenido al país del ocio. Madrid: Ediciones Guadarrama.

Pieper, J. (2003). El ocio y la vida intelectual. Madrid: Ediciones Rialp.

Rojek, C., Shaw, S., y Veal, A. J. (Ed.) (2006). A handbook of Leisure Studies. Great Britain: Palgrave MacMillan.

Russell, B. (1953). Elogio de la ociosidad y otros ensayos. Madrid: Aguilar.

Séneca (2010). Sobre el ocio. España: Alianza Editorial.

Sue, R. (1987). El ocio. México: Fondo de Cultura Económica.

Sloterdijk, P. (2003). Experimentos con uno mismo. Conversación con Carlos Oliveira. Valencia: Pre-Textos.

Sloterdijk, P. (2012). Has de cambiar tu vida. Madrid: PreTextos.

Veblen, T. (2011). Teoría de la clase ociosa. Madrid: Alianza Editorial. 